\title{
MDR1 gene polymorphisms and P-glycoprotein expression in respiratory diseases
}

\author{
Maja Milojkovica, Nena Milacic ${ }^{b}$, Jelena Radovica ${ }^{\mathrm{a}}$ Srdjan Ljubisavljevic ${ }^{\mathrm{a}}$
}

\begin{abstract}
Background. P-glycoprotein (P-gp/MDR1), a member of the ATP-binding cassette (ABC) transporters super family, encoded by the $A B C B 1 / M D R 1$ gene, is one of suggested respiratory tract protection components, found in various tissues with a barrier function, such as tracheobronchial epithelium and lung parenchyma. As an ATP-dependent pump, P-gp extrudes lipophilic particles out of cells and acts as a gatekeeper against numerous xenobiotics, with a protective role in mediating DNA damage, secretion of toxic compounds, apoptosis and the immune response. Therefore, a presence of MDR1 polymorphisms and altered P-gp expression may be important for pathogenesis of reduced lung inflammatory response on cigarette smoke exposure, as well as for the severity of chronic obstructive pulmonary disease and lung cancer pathogenesis and treatment efficacy.

Methods and Results. We have analyzed data available from experimental and clinical studies performed to establish the role of MDR1 polymorphisms, especially the 3435C > T variation, and P-gp expression in pathogenesis and clinical outcome of human respiratory diseases.

Conclusions. Although there are indications that altered expression of P-gp and/or polymorphisms of MDR1 gene play an important role in respiratory diseases pathogenesis and treatment, their exact role and relevance are insufficiently investigated, with exception of certain chemotherapeutic agents' efficacy in lung cancer treatment. Further research in this field, including bigger series of patients, is necessary for better understanding of respiratory diseases' pathogenesis and treatment.
\end{abstract}

Key words: P-gp expression, MDR1 polymorphisms, respiratory diseases, COPD, lung cancer

Received: November 25, 2013; Accepted with revision: June 4, 2014; Available online: June 23, 2014 http://dx.doi.org/10.5507/bp.2014.032

alnstitute of Pathophysiology, Medical Faculty, University of Nis, Serbia ${ }^{b}$ Clinic of Internal Medicine, Department of Pulmology, Clinical Center of Montenegro, Podgorica, Montenegro Corresponding author: Maja Milojkovic, e-mail:maja@medfak.ni.ac.rs

\section{INTRODUCTION}

Human respiratory system is continuously exposed to environmental pathogens, irritants, pollutants and agents which produce oxidative stress. Therefore, the existence of various defense mechanisms throughout respiratory system is essential. At the cellular level, one of the most important protective mechanisms is to pump toxins out of cells, with help of transporting protein systems commonly found in the cell membranes of many organisms, from bacteria to mammals, responsible for cell protection. Many multidrug resistance protein (MDR) group members, present in virtually every cell of all species, can act as drug efflux pumps, resulting in decreased intracellular concentrations of toxic compounds at the site of action ${ }^{1}$. The prominent expression of P-glycoprotein (P-gp, product of $M D R l$ gene) and other MDR proteins throughout respiratory tract indicate that these transporters may be important for protection against endogenous or exogenous toxic compounds entering the lungs ${ }^{2}$. However, this protection seems to reverse if some change in genetic structure of MDRI gene is present, or when P-gp expression is altered. These changes affect the natural protection of respiratory tract by accumulation of toxic compounds (i.e. tobacco smoke constituents) when P-gp activity is reduced. Furthermore, if P-gp is overexpressed, xenobiotics are metabolized rapidly and expelled out of cells, which is especially important for lung cancer treatment, leading to the reduced efficacy of chemotherapeutic drugs used in lung cancer patients.

\section{Human MDR1 gene structure and variations}

The multi-drug resistance-1 (MDRI) gene is located on human chromosome 7 and encodes a 170-kDa plasma membrane glycoprotein (P-gp), a member of the ATPbinding cassette $(\mathrm{ABC})$ transporters super family, also known as $A B C B 1$. The MDRI gene is composed of $28 \mathrm{ex}-$ ons ranging in size from 49 to 209 base pairs (bps) encoding an mRNA of $4.5 \mathrm{~kb}$. Polymorphisms of MDR-1 gene were first described by Hoffmeyer et al. who found a correlation between lower intestinal expression of P-gp and a polymorphism in exon $26\left(\right.$ ref. $\left.^{3}\right)$. Initially, only 15 different SNPs were found in the exons of $A B C B 1$, later increasing to total of at least $50 \mathrm{SNPs}$ and insertion/deletion polymorphisms identified ${ }^{4,5}$. Many of these SNPs are silent (synonymous), and do not produce a change in amino acid sequence. Studies of different ethnic groups suggested that polymorphisms found in $A B C B 1$ denoted as $1236 \mathrm{C}>\mathrm{T}, 2677 \mathrm{G}>\mathrm{T} / \mathrm{A} / \mathrm{C}$, and $3435 \mathrm{C}>\mathrm{T}$, are the most common. The $\mathrm{C} 3435 \mathrm{~T}$ single nucleotide polymorphism located in exon 26 of the MDRl gene was shown to be associated with P-gp levels and substrate uptake ${ }^{3}$. Individuals 
who were homozygous for the T-allele had a significantly decreased P-gp expression level compared to those homozygous for the C-allele. ABCB1 synonymous SNPs $1236 \mathrm{C}>\mathrm{T}$ and $3435 \mathrm{C}>\mathrm{T}$ are linked to a non-synonymous SNP (2677G>T, Ala893Ser) ( ref. $^{6}$ ) and occur with slightly different, but similar frequency in European populations, while their presence is statistically significantly different in ethnic groups of African and Asian origin?

\section{Structure and expression sites of P-gp}

The human MDRI mRNA encodes P-gp, a polypeptide with 1280 amino acids, also known as ABCB1. The protein is defined as having two halves, each containing six hydrophobic trans-membrane domains, and an ATP binding domain. The two halves are separated by a flexible linker region, and the two ATP-binding domains are structurally similar. All 12 trans-membrane domains are found in the plasma membrane ${ }^{8}$. P-gp is expressed in the apical membrane of cells with excretory functions, such as those in the liver, kidney, small intestine, stomach, and the blood-brain barrier ${ }^{9,10}$. The physiological expression of P-gp in tissues is an important determinant for drug detoxification in various cells and tissues. This protein also mediates the transfer blocking of hydrophobic xenobiotics across the placenta and prevention of the entry of substrates into the central nervous system as a part of the blood-brain barrier ${ }^{10}$. A novel investigation has recently shown that P-gp is also expressed within cells and localized to lysosomes, allowing P-gp mediated lysosomal sequestration of xenobiotics ${ }^{11}$.

Genetic variants of $M D R 1$ can influence interindividual variability in the bioavailability and pharmacokinetics of various drugs ${ }^{12,13}$. Some findings suggested that $3435 \mathrm{C}>\mathrm{T}$ was associated with significantly reduced intestinal P-gp expression in $\mathrm{T} / \mathrm{T}$ homozygotes in comparison with subjects homozygous for $\mathrm{C}$ allele $(\mathrm{C} / \mathrm{C})$, leading to higher steady state plasma concentrations after the oral administration of digoxin ${ }^{13,14}$. However, a large number of the subsequent human studies shown the inconsistent observations even when the same drugs were tested, in the same disease and ethnic group ${ }^{14,15}$.

\section{MDR1 gene, P-gp and lungs}

Tissues with a barrier function, such as lung parenchyma and tracheobronchial epithelium, have high transcriptional activity for many $\mathrm{ABC}$ transporters ${ }^{16,17}$. In human lung, P-gp is expressed at the apical side of ciliated epithelial cells or ciliated collecting ducts, and on apical and lateral surfaces of serous cells of bronchial glands but not in mucus-secreting goblet cells ${ }^{18}$. Epithelial cells of the trachea and major bronchi stained strongly for P-gp while staining of the smaller bronchi is patchy or absent. P-gp was also found in the lateral membranes of normal nasal respiratory mucosa ${ }^{19}$. In human and rat type I epithelium, P-gp is located at the luminal side whereas freshly isolated type II cells lack P-gp ${ }^{20}$. In study performed by Cordon-Cardo et al., pneumocytes did not stain for P-gp ${ }^{21}$. Some antibodies visualized P-gp in endothelial cells of blood vessels ${ }^{18,21}$. Alveolar and blood monocyte-derived macrophages stained positive but variably for $\mathrm{P}-\mathrm{gp}^{2}$. The observed apical epithelium expression may signify that P-gp is important for transport of compounds from the interstitium into the lumen, although the precise function of P-gp in the lungs remains unknown.

\section{Animal models}

Rodents contain two Mdrl genes, denoted as Mdrla and Mdrlb. Scheffer et al. reported high P-gp levels in lungs of mice ${ }^{2}$. In mice orally treated with dexamethasone for $24 \mathrm{~h}, M d r 1 b$ mRNA expression in lungs was decreased, and that finding was a base for speculation that dexamethasone treatment of lung tumors may reverse MDR $\left(\right.$ ref. $\left.^{22}\right)$. In the lung tissue of $M d r l a / 1 b(-/-)$ mice $^{23}$, the level of $[3 \mathrm{H}]$ digoxin was rather low compared to brain, ovary and adrenal glands, and it was measured 2.6 times higher in (-/-) mice than in $(+/+)$ mice, but this was not significant.

In research by van der Deen et al., triple knock-out (TKO) mice lacking the genes for Mrpl and Mdrla/lb were more susceptible to develop COPD features than the wild-type (WT) experimental animals ${ }^{24}$. In their experimental work, TKO and WT mice (six per group) were exposed to 2 cigarettes twice daily by nose-only exposure or room air for 6 months. It was found that Mrp I/ $M d r 1 a / 1 b$ knock-out mice had a reduced inflammatory response to cigarette smoke, and lower expression levels of several cytokines and chemokines in lungs independent of smoke exposure. It was suggested that dysfunction of MDR 1 might be one of contributing factors for reduced inflammatory response to inhalation of cigarette smoke and insufficient clearance of toxic substance as a result of its impaired function ${ }^{24}$.

In rats, $M d r l a$ and $M d r l b$ mRNA expression were found to be highest in the ileum ${ }^{25}$. The Mdrla expression level in rat lung was $2 \%$ of the expression in ileum and expression of $M d r 1 b$ was $47 \%$ of that in ileum. For the purpose of in vivo study of P-gp distribution, nude rats were injected with a P-gp overexpressing small cell lung cancer (SCLC) cell line (GLC4/P-gp) and with a P-gp negative cell line (GLC4) $\left(\right.$ ref. $^{26}$ ). P-gp function was visualized with radiolabeled P-gp substrate [11C] verapamil by positron emission tomography (PET) with or without P-gp modulator cyclosporine A. The accumulation of [11C] verapamil was significantly increased by cyclosporine $\mathrm{A}$ in brains and GLC4/P-gp tumors in these rats. In all other investigated organs including lungs, the accumulation after cyclosporine A treatment was unaltered.

In intact rabbit lung, vascular P-gp kinetics was measured in vivo using the lipophilic amine dye rhodamine 6G (R6G) by measuring R6G in the perfusate during circulation ${ }^{27}$. Inhibition of P-gp function with verapamil or GF120918 resulted in higher accumulation of R6G in lung. It was proposed that the opposite would happen when epithelial P-gp was inhibited because R6G would then be retained in the airspace. Authors suggested that the inhibition of epithelial P-gp could also result in higher R6G accumulation, with consequent inhibition of $\mathrm{R} 6 \mathrm{G}$ transport to the lumen which could be compensated by reversed transport to the interstitial side where it either might be retained in the tissue or transported into the 
circulation $^{27}$. This model could be useful in testing a large variety of pulmonary therapeutic agents, such as corticosteroids and sympathicomimetics that may be substrates for transporters in the lung or modulate their activity.

\section{In vitro studies of $M D R 1$ - respiratory cell lines and tumor cells}

Different approaches have been employed for in $v i$ tro investigations of P-gp expression and functionality in respiratory cell lines and lung cancer cells. One of cell lines used for drug metabolism studies is the immortalized human bronchial epithelial cell line 16HBE140-, which resembles primary epithelium ${ }^{28}$. In these cells, P-gp functional activity was measured with P-gp substrate rhodamine 123 and its transport was inhibited by verapamil ${ }^{29}$. In research by Hamilton et al., two lung cell lines, Calu3 (suitable for drug transport studies because of tight junction formation in cell culture) and A549 cells, were compared for P-gp expression and functionality ${ }^{30}$. P-gp expression was higher in A549 cells than in Calu-3 cells, although the efflux of rhodamine 123 was higher in Calu3 cells. This may be explained by additional and overlapping activity of other $\mathrm{ABC}$ transporters in these cells ${ }^{31}$.

In primary rat alveolar type II cells, $M d r 1 b$ mRNA levels increased in a time dependent manner in cultures at day 1, 2 and 3 compared to freshly isolated cells. Mdrlb mRNA was present at low levels and increased after oxygen radical induction with paraquat ${ }^{32}$. In freshly isolated primary human bronchial epithelial cells, P-gp was present and increased after 24 hours paraquat exposure. Also, rhodamine 123 efflux was detectable in these cells, which proved functional activity of P-gp ( ref. $^{32}$ ), and demonstrated that expression of P-gp is greater during stress, probably as a consequence of radical production and in vitro culturing or differentiation.

\section{$M D R 1$ in respiratory diseases}

The influence of MDRI polymorphisms and P-gp protein expression on side effects and clinical responses to important drugs was broadly investigated, especially considering anti-neoplastic agents, antidepressants and immunosuppressant ${ }^{1}$. A large number of studies have also focused on the associations between MDR 1 polymorphisms and pathogenesis of various diseases, to mention only few - Parkinson's disease, epilepsy, SLE, inflammatory bowel diseases, cancers and renal disease, rheumatoid arthritis, hypertension ${ }^{9}$ and FMF (Familial Mediterranean fever) (ref. $\left.{ }^{33}\right)$. The impact of $M D R 1$ polymorphisms and level of P-gp protein expression on lung diseases is still speculative, but some authors propose that polymorphisms in the MDRl gene may be clinically important particularly in patients with cystic fibrosis, since it was found that one of $\mathrm{ABC}$ transporters, a cystic fibrosis transmembrane conductance regulator (CFTR) mutations, are responsible for the onset of that disease ${ }^{34}$. A certain degree of correlation was also suggested in COPD (ref. ${ }^{35}$ ), as well as in lung cancer pathogenesis and treatment.

\section{MDR1 and COPD}

Chronic obstructive pulmonary disease (COPD) is a major cause of morbidity and mortality worldwide ${ }^{36}$. In addition to genetic and other environmental factors, smoking contributes to the development of COPD by overloading of detoxification system and causing the imbalance within the protease-anti-protease system. Results of some studies suggested that P-gp protein plays a role in combating the toxic effect of smoking and in the removal of oxidative stress metabolites ${ }^{37,38}$. The gene has also been shown to play a role in cellular regeneration ${ }^{39}$. In the study performed by van der Deen et al., MDR proteins exhibited a protective effect against oxidative stress. It was found that COPD patients had a decreased level of MDR proteins in their bronchial epithelium ${ }^{40}$. Other authors have detected reduced P-gp expression and activity during inflammation ${ }^{41}$. In the study by Dogan et al., forty-one participants with COPD were genotyped for MDR-1 3435C/T polymorphism. When compared to the control group, participants with COPD were significantly more frequently homozygous and heterozygous for $M D R 1$ C3435T polymorphism ${ }^{35}$. The T-allele frequency was significantly higher in COPD patients when compared to the healthy control participants (52\% and $19 \%$, respectively). These findings suggest that $M D R-1$ may play a role in the development of COPD through some inflammatory and detoxification mechanisms.

\section{MDR1 in lung tumors}

Data suggest that P-gp expression in lung cancer is initially small, but changeable, and increasing with disease evolution as a consequence of the acquired resistance to the cancer chemotherapy ${ }^{42}$. Besides, some studies have shown higher P-gp expression at the invasion front of lung tumors and it was suggested that P-gp expression is in a positive correlation with invasion potential of tumor cells $^{43}$. However, in a study performed by Cordon-Cardo et al., only two out of 22 non-small cells lung carcinoma (NSCLC) samples (both adenocarcinomas) stained positive with three P-gp antibodies and no P-gp was detected on pulmonary carcinoids ${ }^{21}$. The possible effect of $M D R 1$ polymorphisms was also studied in tobacco-related lung cancer, but no clear association was found between the $\mathrm{T} / \mathrm{T}$ genotype of the C3435T polymorphism and susceptibility to lung cancer in a group of 268 Caucasian men who were current smokers ${ }^{44}$.

An altered P-gp expression can imply the efficacy of lung cancer chemotherapeutic treatment. Level of P-gp expression might impair the intracellular retention of anticancer drugs including vinca alkaloids, taxanes ${ }^{45}$, cisplatinum $^{46}$, and others. The presence of MDRl gene polymorphisms could be a cause of this changed expression, especially MDR1 $3435 \mathrm{C}$ and $2677 \mathrm{G}$, which were found to be associated with the lower P-gp expression and consecutive better response to docetaxel chemotherapy ${ }^{47}$. However, these results are not in consent with previous data by Isla et al., in which no relation was found between SNP C3435T in MDR 1 and survival in 62 docetaxel cisplatin treated NSCLC patients ${ }^{48}$. In another research, 
a relation between $\mathrm{P}$-gp and glutathione $\mathrm{S}$-transferase pi (GST-pi) expression in NSCLC exposed in vitro to doxorubicin was revealed ${ }^{49}$, suggesting that these two factors play a role in doxorubicin resistance. There was also a correlation between current smoking and doxorubicin resistance of NSCLC. Forty-two out of 72 NSCLC smokers expressed P-gp, whereas only two out of 22 tumors of non-smokers were P-gp positive ${ }^{50}$.

In cancer therapy, many attempts have been made to reverse MDR mechanisms. However, in a randomized double-blind trial in 130 SCLC patients no positive effects were seen with the P-gp modulator megestrol acetate in addition to chemotherapeutic drugs, suggesting that levels of P-gp expression in lung tumors were not relevant or that modulation of P-gp activity was not complete in this treatment ${ }^{51}$. Although immunosuppressive agents such as cyclosporine A and tacrolimus (both calcineurin antagonists) are P-gp substrates, no relation was found of MDR1 G2677T and C3435T genotypes with tacrolimus blood levels in 83 lung transplant patients treated with tacrolimus $^{52}$. Altogether, these data implicate that there is still no clear association between $M D R 1$ polymorphisms and effects on outcome of treatment of lung cancer or lung transplant patients.

In the investigation by Trussardi-Regnier et al., expression of three major resistance genes MDRl, MRPI and $L R P$ was simultaneously investigated in small cell lung cancer, non-small cell lung cancer and metastasis ${ }^{53}$. Single biopsies of bronchoscopy from 73 patients were performed to investigate expression of these three resistance genes by reverse transcriptase-polymerase chain reaction. Relations between gene expression and patient age, smoking status, histology, and chemotherapy were evaluated. A more frequent expression of MDRl (77 versus $66 \%$ ), $M R P I$ (91 versus $72 \%$ ) and $L R P(77$ versus $63 \%$ ) genes was detected in the malignant biopsies than in the non-malignant, respectively. In the metastasis biopsies, expression of these genes was markedly increased. Biopsies from progressing cancer showed higher MDR I, MRPI and $L R P$ gene expression. These findings have revealed the high gene expression of MDRI and MRPI in relapsed diseases $^{53}$.

\section{CONCLUSION}

Although the physiological role of $M D R 1$ is already well-known and widely investigated, the exact implications of its polymorphisms and P-gp expression in respiratory diseases are still speculative. One of possible reasons for that is the complexity of lung architecture, which makes research on detailed cellular processes very challenging. There are numerous proofs that $\mathrm{ABC}$ transporters in general are very highly expressed in the lung. The best evidences so far have been obtained from experimental models, in which the exposure to cigarette smoke in ABC transporter deficient animal models was investigated. The finding of a reduced inflammatory response and lower expression levels of several cytokines and chemokines in lungs could be a suggestive result, leading to the con- clusion that dysfunction of MDRI might be one of contributing factors for reduced inflammatory response to inhalation of cigarette smoke and inadequate clearance of harmful matters as a result of its impaired function. Although scarce, there are also results which indicate that presence of MDR1 $3435 \mathrm{C} / \mathrm{T}$ polymorphism could contribute to the development of COPD in humans. Unfortunately, only a small number of patients were included in investigations so far, insufficient to make a clear conclusion about the clinical relevance of $M D R 1$ genotyping in COPD patients.

Cell line models have been used to study transport processes and pulmonary drug metabolism. The delivery of pulmonary drugs to the site of action is probably highly dependent on the presence and activity of many ABC transporters, and MDRl as one of them, in several cell types in the lung. The first barrier after inhalation is the pulmonary epithelium and transporters in the pulmonary endothelium may be critical for the delivery of intravenously or orally administered drugs. Our present knowledge is not extensive enough for a clear and clinically useful conclusion about the modifications in bioavailability of drugs used for treatment of lung cancer and their efficacy, related to $M D R I$ expression. Therefore, the more in-depth research considering the P-gp expression and genotyping of $M D R 1$ in respiratory diseases is essential, in order to define its role in biology of respiratory diseases, and probably even more important, to personalize the treatment and answer the questions about evolution and prognosis of severe respiratory problems.

\section{ACKNOWLEDGEMENT}

Author contributions: MM, JR: literature search and manuscript writing, NM, SL: literature search and critical reading, all authors: manuscript revision.

Conflict of interest statement: None declared.

\section{REFERENCES}

1. Dean $M$, Hamon $Y$, Chimini G. The human ATP-binding cassette (ABC) transporter superfamily. J Lipid Res 2001;42:1007-17.

2. Scheffer GL, Pijnenborg AC, Smit EF, Muller M, Postma DS, Timens W, van der Valk P, de Vries EG, Scheper RJ. Multidrug resistance related molecules in human and murine lung. J Clin Pathol 2002;55:332-9.

3. Hoffmeyer S, Burk O, von Richter O, Arnold HP, Brockmoller J, Johne A, Cascorbi I, Gerloff T, Roots I, Eichelbaum M, Brinkmann $\mathrm{U}$. Functional polymorphisms of the human multidrug-resistance gene: multiple sequence variations and correlation of one allele with P-glycoprotein expression and activity in vivo. Proc Natl Acad Sci USA 2000;97:3473-8.

4. Cascorbi I, Gerloff T, Johne A, Meisel C, Hoffmeyer S, Schwab M, Schaeffeler E, Eichelbaum M, Brinkmann U, Roots I. Frequency of single nucleotide polymorphisms in the P-glycoprotein drug transporter MDR1 gene in white subjects. Clin Pharmacol Ther 2001;69:169-74.

5. Kroetz DL, Pauli-Magnus C, Hodges LM, Huang CC, Kawamoto M, Johns SJ, Stryke D, Ferrin TE, DeYoung J, Taylor T, Carlson EJ, Herskowitz I, Giacomini KM, Clark AG. Pharmacogenetics of Membrane Transporters Investigators: Sequence diversity and haplotype structure in the human ABCB1 (MDR1, multidrug resistance transporter) gene. Pharmacogenetics 2003;13:481-94. 
6. Tang K, Wong LP, Lee EJ, Chong SS, Lee CG. Genomic evidence for recent positive selection at the human MDR1 gene locus. Hum Mol Genet 2004;13:783-97.

7. Milojkovic M, Stojnev S, Jovanovic I, Ljubisavljevic S, Stefanovic V, Sunder-Plassman R. Frequency of the C1236T, G2677T/A and C3435T MDR1 gene polymorphisms in the Serbian population. Pharmaco Rep 2011;63:808-14.

8. Fung $\mathrm{KL}$, Gottesman MM. A synonymous polymorphism in a common MDR1 (ABCB1) haplotype shapes protein function. Biochimica Biophysica Acta 2009;1794:860-71.

9. Ieri I. Functional significance of genetic polymorphisms in P-glycoprotein (MDR1, ABCB1) and breast cancer resistance protein (BCRP, ABCG2). Drug Metab Pharmacokinet 2012;27:85-105.

10. Schinkel AH, Wagenaar E, Mol CA, van Deemter L. P-glycoprotein in blood-brain barrier of mice influences the brain penetration and pharmacological activity of many drugs. J Clin Invest 1996;97:251724.

11. Yamagishi T, Sahni S, Sharp DM, Arvind A, Jansson PJ, Richardson DR. P-glycoprotein mediates drug resistance via a novel mechanism involving lysosomal sequestration. J Biol Chem 2013;288:31761-71.

12. Schwab M, Eichelbaum M, Fromm MF. Genetic polymorphisms of the human MDR1 drug transporter. Annu Rev Pharmacol Toxico 2003:43:285-307.

13. Kurata Y, leiri I, Kimura M, Morita T, Irie S, Urae A, Ohdo S, Ohtani H, Sawada Y, Higuchi S and Otsubo K. Role of human MDR1 gene polymorphism in bioavailability and interaction of digoxin, a substrate of P-glycoprotein. Clin Pharmacol Ther 2002;72:209-19.

14. Hoffmeyer S, Burk O, von Richter O, Arnold HP, Brockmoller J, Johne A, Cascorbi I, Gerloff T, Roots I, Eichelbaum M, Brinkmann $U$. Functional polymorphisms of the human multidrugresistance gene: multiple sequence variations and correlation of one allele with P-glycoprotein expression and activity in vivo. Proc Natl Acad Sci USA 2000;97:3473-8.

15. Bazrafshani MR, Poulton KV, Mahmoodi M. A linkage and association analysis study in the multidrug resistance gene 1 (MDR1) in renal patients. Int J Mol Epidemiol Genet 2012;3:314-20.

16. Langmann T, Mauerer R, Zahn A, Moehle C, Probst M, Stremmel W, Schmitz G: Real-time reverse transcription-PCR expression profiling of the complete human ATP-binding cassette transporter superfamily in various tissues. Clin Chem 2003;49:230-8.

17. Scheffer GL, Pijnenborg AC, Smit EF, Muller M, Postma DS, Timens W van der Valk P, de Vries EG, Scheper RJ. Multidrug resistance related molecules in human and murine lung. J Clin Pathol 2002;55:332-9.

18. Lechapt-Zalcman E, Hurbain I, Lacave R, Commo F, Urban T, Antoine M, Milleron B, Bernaudin JF. MDR1-Pgp 170 expression in human bronchus. Eur Respir J 1997;10:1837-43.

19. Wioland MA, Fleury-Feith J, Corlieu P, Commo F, Monceaux G, LacauSt-Guily J, Bernaudin JF. CFTR, MDR1, and MRP1 immunolocalization in normal human nasal respiratory mucosa. J Histochem Cytochem 2000;48:1215-22

20. Campbell L, Abulrob AN, Kandalaft LE, Plummer S, Hollins AJ, Gibbs A, Gumbleton M. Constitutive expression of p-glycoprotein in normal lung alveolar epithelium and functionality in primary alveolar epithelial cultures. J Pharmacol Exp Ther 2003;304:441-52.

21. Cordon-Cardo C, O'Brien JP, Boccia J, Casals D, Bertino JR, Melamed MR. Expression of the multidrug resistance gene product ( $\mathrm{P}$ glycoprotein) in human normal and tumor tissues. J Histochem Cytochem 1990;38:1277-87.

22. Scomma H, Lechevalier E, Lacarelle B, Barra Y. Modulation of MDR1 and CYP3A expression by dexamethasone: evidence for an inverse regulation in adrenals. Biochem Biophys Res Commun 1998;252:392 5.

23. Schinkel AH, Mayer U, Wagenaar E, Mol CA, van Deemter L, Smit J, van der Valk MA, Voordouw AC, Spits H, van Tellingen O, Zijlmans JM Fibbe WE, Borst P. Normal viability and altered pharmacokinetics in mice lacking MDR1-type (drug-transporting) Pglycoproteins. Proc Natl Acad Sci USA 1997:94:4028-33.

24. Van der Deen M, Timens W, Timmer-Bosscha H, van der Strate BW, Scheper RJ, Postma DS, de Vries EG, Kerstjens HA. Reduced inflammatory response in cigarette smoke exposed Mrp1/Mdr1a/1b deficient mice. Respir Res 2007:8:49.

25. Brady JM, Cherrington NJ, Hartley DP, Buist SC, Li N, Klaassen CD. Tissue distribution and chemical induction of multiple drug resistance genes in rats. Drug Metab Dispos 2002;30:838-44.
26. Hendrikse NH, de Vries EG, Eriks-Fluks L, van der Graaf WT, Hospers GA, Willemsen AT, Vaalburg W, Franssen EJ. A new in vivo method to study P-glycoprotein transport in tumors and the blood-brain barrier. Cancer Res 1999:59:2411-6.

27. Roerig DL, Audi SH, Ahlf SB. Kinetic characterization of p-glycoprotein-mediated efflux of rhodamine $6 \mathrm{~g}$ in the intact rabbit lung. Drug Metab Dispos 2004;32:953-8.

28. Forbes II. Human airway epithelial cell lines for in vitro drug transport and metabolism studies. Pharm Sci Technol Today 2000;3:18-27.

29. Ehrhardt C, Kneuer C, Laue M, Schaefer UF, Kim KJ, Lehr CM. 16HBE140- human bronchial epithelial cell layers express P-glycoprotein, lung resistance-related protein, and caveolin-I. Pharm Res 2003;20:545-51.

30. Hamilton KO, Yazdanian MA, Audus KL. Modulation of P-glycoprotein activity in Calu-3 cells using steroids and beta-ligands. Int J Pharm 2001;228:171-9.

31. Hamilton KO, Topp E, Makagiansar I, Siahaan T, Yazdanian M, Audus $\mathrm{KL}$. Multidrug resistance-associated protein-1 functional activity in Calu-3 cells. J Pharmacol Exp Ther 2001;298:1199-205.

32. Lehmann T, Kohler C, Weidauer E, Taege C, Foth H. Expression of MRP1 and related transporters in human lung cells in culture. Toxicology 2001;167:59-72.

33. Rüstemoglu A, Gumus-Akay G, Yigit S, Tasliyurt T. Analysis of common MDR1 (ABCB1) gene C1236T and C3435T polymorphisms in Turkish patients with Familial Mediterranean Fever. Genet Mol Res 2011;14:3411-20.

34. Riordan JR, Rommens JM, Kerem B, Alon N, Rozmahel R, Grzelczak Z, Zielenski J, Lok S, Plavsic N, Chou JL. Identification of the cystic fibrosis gene: cloning and characterization of complementary DNA. Science 1989;245:1066-73.

35. Dogan OT, Katrancioglu N, Karahan O, Sanli GC, Zorlu A, Manduz S. Frequency of the MDR-1 C>T gene polymorphism in patients with COPD. Clinics (Sao Paulo) 2010;65:1115-7.

36. Global strategy for the diagnosis, management, and prevention of chronic obstructive pulmonary disease (updated 2013). GOLD. Available from: http://www.goldcopd.org/uploads/users/files/ GOLD_Report_2013_Feb20.pdf.

37. Izzotti A, Cartiglia C, Longobardi M, Balansky RM, D'agostino F, Lubet $\mathrm{RA}$, De Flora S. Alterations of gene expression in skin and lung of mice exposed to light and cigarette smoke. FASEB J 2004;18:1559-61.

38. Papp E, Gadawski I, Cote HC. Longitudinal effects of thymidine analogues on mtDNA, mtRNA and multidrug resistance (MDR-1) induction in cultured cells. J Antimicrob Chemother 2008;61:1048-52.

39. Israeli D, Ziaei S, Gonin P, Garcia L. A proposal for the physiological significance of mdr1 and Bcrp1/Abcg2 gene expression in normal tissue regeneration and after cancer therapy. J Theor Biol 2005:232:41-5.

40. Van der Deen M, Marks $H$, Willemse BW, Postma DS, Mueller M, Smit EF, Scheffer GL, Scheper RJ, de Vries EG, Timens W. Diminished expression of multidrug resistance-associated protein 1 (MRP1) in bronchial epithelium of COPD patients. Virchows Arch 2006;449:6828.

41. Piquette-Miller M, Pak A, Shahzamani A. Decreased Expression and Activity of P-Glycoprotein in Rat Liver During Acute Inflamation. Pharmaceut Res 1998;15:706-11.

42. Fardel O, Lecureur V, Guillouzo A. The P-glycoprotein multidrug transporter. Gen Pharmacol 1996;27:1283-91

43. Beer TW, Rowlands DC, Crocker J. Detection of the multidrug resistance marker P-glycoprotein by immunohistochemistry in malignant lung tumours. Thorax 1996;51:526-9.

44. Sinues B, Fanlo A, Bernal ML, Mayayo E, Bello S, Rubio E, Isla D. MDR1 C3435T genetic polymorphism and tobacco-related lung cancer. Oncology 2003;64:183-5.

45. Eichelaum M, Fromm MF, Schwab M. Clinical aspects of the MDR1 (ABCB1) gene polymorphism. Ther Drug Monit 2004;26:180-5

46. Sohn JW, Lee SY, Lee SJ, Kim EJ, Cha SI, Kim CH, Lee JT, Jung TH, Park JY. MDR1 polymorphisms predict the response to etoposidecisplatin combination chemotherapy in small cell lung cancer. Jpn J Clin Oncol 2006;36:137-41.

47. Pan JH, Han JX, Wu JM, Huang HN, Yu QZ, Sheng LJ. MDR1 single nucleotide polymorphism G2677T/A and haplotype are correlated with response to docetaxel-cisplatin chemotherapy in patients with non-small-cell lung cancer. Respiration 2009;78:49-55.

48. Isla D, Sarries C, Rosell R, Alonso G, Domine M, Taron M, LopezVivanco G, Camps C, Botia M, Nunez L, Sanchez-Ronco M, Sanchez 
JJ, Lopez-Brea M, Barneto I, Paredes A, Medina B, Artal A, Lianes P. Single nucleotide polymorphisms and outcome in docetaxelcisplatin- treated advanced non-small-cell lung cancer. Ann Oncol 2004; 15:1194-203.

49. Volm M, Mattern J, Samsel B. Relationship of inherent resistance to doxorubicin, proliferative activity and expression of Pglycoprotein 170 , and glutathione S-transferase-pi in human lung tumors. Cancer 1992;70:764-9.

50. Volm M, Mattern J, Samsel B. Overexpression of P-glycoprotein and glutathione S-transferase-pi in resistant non-small cell lung carcinomas of smokers. Br J Cancer 1991;64:700-4.
51. Wood L, Palmer M, Hewitt J, Urtasun R, Bruera E, Rapp E, Thaell JF. Results of a phase III, double-blind, placebo-controlled trial of megestrol acetate modulation of P-glycoprotein-mediated drug resistance in the first-line management of smallcell lung carcinoma. Br J Cancer 1998;77:627-31.

52. Zheng H, Zeevi A, Schuetz E, Lamba J, McCurry K, Griffith BP, Webber S, Ristich J, Dauber J, lacono A, Grgurich W, Zaldonis D, McDade $\mathrm{K}$, Zhang J, Burckart GJ. Tacrolimus dosing in adult lung transplant patients is related to cytochrome P4503A5 gene polymorphism. J Clin Pharmacol 2004;44:135-40.

53. Trussardi-Regnier A, Millot JM, Gorisse MC, Delvincourt C, Prevost A. Detection of drug-resistance genes using single bronchoscopy biopsy specimens. Oncol Rep 2007;18:703-8. 